\title{
Vacuum Large Current Parallel Transfer Numerical Analysis
}

\author{
Enyuan Dong, ${ }^{1}$ Shengkai Hou, ${ }^{1}$ Xiang Zheng, ${ }^{2}$ Taotao Qin, ${ }^{1}$ Guixin Liu, ${ }^{1}$ and Bing Zhao ${ }^{1}$ \\ ${ }^{1}$ College of Electrical Engineering, Dalian University of Technology, Dalian 116024, China \\ ${ }^{2}$ School of Electronics and Information Engineering, Dalian Jiaotong University, Dalian 116028, China
}

Correspondence should be addressed to Enyuan Dong; dey@dlut.edu.cn

Received 17 April 2014; Revised 19 May 2014; Accepted 19 May 2014; Published 3 August 2014

Academic Editor: Peng Shi

Copyright (C) 2014 Enyuan Dong et al. This is an open access article distributed under the Creative Commons Attribution License, which permits unrestricted use, distribution, and reproduction in any medium, provided the original work is properly cited.

\begin{abstract}
The stable operation and reliable breaking of large generator current are a difficult problem in power system. It can be solved successfully by the parallel interrupters and proper timing sequence with phase-control technology, in which the strategy of breaker's control is decided by the time of both the first-opening phase and second-opening phase. The precise transfer current's model can provide the proper timing sequence to break the generator circuit breaker. By analysis of the transfer current's experiments and data, the real vacuum arc resistance and precise correctional model in the large transfer current's process are obtained in this paper. The transfer time calculated by the correctional model of transfer current is very close to the actual transfer time. It can provide guidance for planning proper timing sequence and breaking the vacuum generator circuit breaker with the parallel interrupters.
\end{abstract}

\section{Introduction}

With the rapid development of the power system and the increase of the transmission capacity, it requires safer and more stable environment. The fault current's breaking capacity and the longevity of high voltage circuit breaker that controls and protects power system are essential to the reliable operation of electric power systems. It can effectively reduce the average arcing time and peak arc current to use synchronous technology [1] to control the separate moment of breaker's contacts through the zero point and it is useful to improve the breaking capacity of circuit breaker and reduce contact's wear [2].

The rated current of single vacuum circuit breaker is less than $5 \mathrm{ka}$. And the single breaker is unable to burden the high rated continuous current and break the large shortcircuit current [3-6]. In order to improve the vacuum circuit breaker's rated current and the capacity of the breaker, two parallel interrupters are used to share a large current especially for the generator circuit breaker and the occasion that needs to break the large current $[7,8]$. However two pairs of contacts are impossible to absolutely separate at the same time due to the manufacture of breakers, the dispersion of actuators, and the arrangement which leads to a failure to break the whole fault current [9].
The parallel vacuum interrupters are used to share the rated large current. When the fault current occurs, main vacuum interrupter (MVI) is opened firstly. The fault current gradually is transferred from MVI to AVI (auxiliary vacuum interrupter). At the same time, the current constantly decays.

At the end of the current-transfer process, the fault current through AVI is removed with phase-control technology [10-12]. But in the transfer process, the multiplication of AVI's inductance and the instantaneous current is greater than MVI's arc voltage, which leads to uncontrollable transfer process and the current cannot transfer from MVI to AVI. The successful breaking of the AVI depends much on the precise calculated transfer time. So an accurate model of the transfer current is needed.

In the paper [13], the mathematical model of transfer current is provided through the relevant theoretical derivation. It is helpful to analyze the transfer process. The arc resistance's value in the model is constant, which leads to a large deviation for transfer time. So this model cannot provide accurate timing sequence for using the phase-control technology [10-12]. The success rate of transferring is related to transfer current's value, the time of breaking MVI, and so forth. This transfer current's model needs to be corrected. In this paper, the vacuum arc resistance's formula is obtained by Matlab through the analysis of experimental data of transfer 


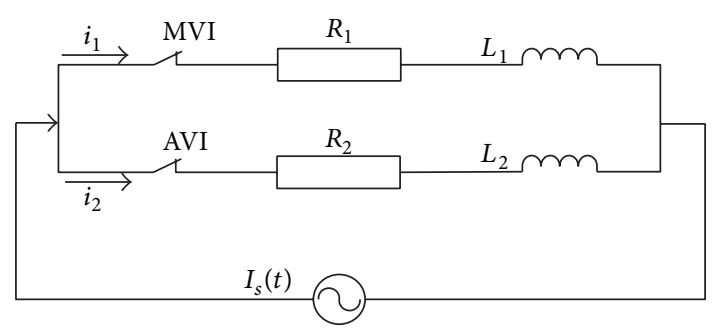

Figure 1: MVI and AVI share the large current.

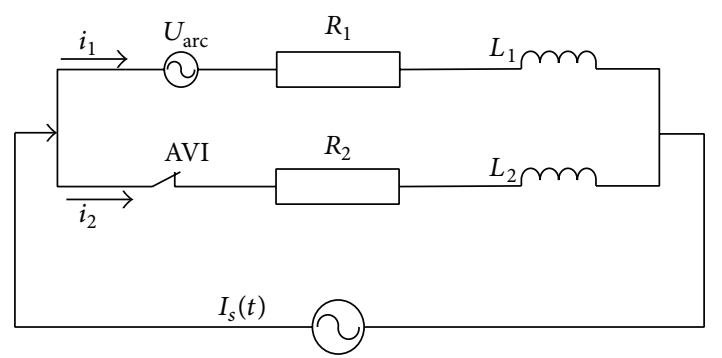

FIGURE 2: Equivalent circuit when MVI's contacts are opened.

current. The arc resistance changes with time and transfer current. Finally, the correctional model of transfer current is derived with the real arc resistance.

\section{The Model of Transfer Current}

At the beginning, the large rated current is shared by MVI and AVI as shown in Figure 1.

When the short-circuit fault occurs, MVI is opened firstly. The large current gradually is transferred from MVI to AVI. The equivalent circuit is shown in Figure 2.

Short-circuit current of the system [13]:

$$
\begin{aligned}
I_{s}(t)= & \sqrt{2} I_{e} \sin \left(\omega t+\alpha-\varphi_{d}\right) \\
& +\left[I_{e} \sin (\alpha-\varphi)-\sqrt{2} I_{e} \sin \left(\alpha-\varphi_{d}\right)\right] e^{-t / \tau_{\mathrm{sys}}} .
\end{aligned}
$$

In (1), $I_{e}$ is the effective value before short circuit occurring. $\tau_{\text {sys }}$ is the decay constant of the system. $\omega$ is the current's angular frequency. $\alpha$ is the initial phase angle of power source's voltage when short circuit occurs instantly. $\varphi_{d}$ is the impedance angle after short circuit occurring. And $\varphi$ is the impedance angle before short circuit occurring.

The impedance of power source can be ignored when it is compared with the interrupter's resistance and the system capacity is much larger. Considering the constant arc voltage $U_{a}$ when the MVI is opened, the transfer current in Figure 2 can be expressed with [9]

$$
\begin{aligned}
& i_{1}+i_{2}=I_{s}(t), \\
& L_{1} \frac{d i_{1}}{d t}+R_{1} i_{1}+U_{a}=L_{2} \frac{d i_{2}}{d t}+R_{2} i_{2}
\end{aligned}
$$

$$
(T 1 \leq t \leq T 2) \text {. }
$$

T1 is the moment of breaking MVI. T2 is the moment of breaking AVI. $R_{1}$ does not contain contact resistance between a pair of contacts when MVI is separated in (2) and it mainly consists of arc resistance and the resistance of internal conductive rod in MVI. So the differential equation (3) is derived from (2):

$$
\begin{aligned}
\frac{d i_{1}}{d t}+\frac{\left(R_{1}+R_{2}\right)}{\left(L_{1}+L_{2}\right)} i_{1}= & \frac{L_{2}}{\left(L_{1}+L_{2}\right)} \frac{d I_{s}(t)}{d t} \\
& +\frac{R_{2}}{\left(L_{1}+L_{2}\right)} I_{s}(t)-\frac{U_{a}}{\left(L_{1}+L_{2}\right)} .
\end{aligned}
$$

$i_{1}$ is the instantaneous value of the transfer current [9] in the following:

$$
\begin{aligned}
i_{1}= & C e^{-\left(\left(R_{1}+R_{2}\right) /\left(L_{1}+L_{2}\right)\right) t}-\frac{U_{a}}{R_{1}+R_{2}} \\
& +\sqrt{2} I_{e} \frac{L_{2}-R_{2} \tau_{\text {sys }}}{\left(L_{1}+L_{2}\right)-\left(R_{1}+R_{2}\right) \tau_{\text {sys }}} e^{-t / \tau_{\text {sys }}} \\
& -\sqrt{2} I_{e} \frac{\omega L_{1} R_{2}-\omega L_{2} R_{1}}{\left(R_{1}+R_{2}\right)^{2}+\omega^{2}\left(L_{1}+L_{2}\right)^{2}} \sin (\omega t) \\
& -\sqrt{2} I_{e} \frac{\left(R_{1}+R_{2}\right) R_{2}+\omega^{2} L_{2}\left(L_{1}+L_{2}\right)}{\left(R_{1}+R_{2}\right)^{2}+\omega^{2}\left(L_{1}+L_{2}\right)^{2}} \cos (\omega t) .
\end{aligned}
$$

In (4), $\varphi_{d}$ is $\pi / 2 . R_{1}$ is the equivalent resistance of MVI's branch. $L_{1}$ is the equivalent inductance of MVI's branch. $R_{2}$ is the equivalent resistance of AVI's branch. $L_{2}$ is the equivalent inductance of AVI's branch. $T_{k}$ is the moment at which MVI is opened. The differential constant $C$ is shown in the following:

$$
\begin{aligned}
& C=e^{\left(\left(R_{1}+R_{2}\right) /\left(L_{1}+L_{2}\right)\right) T_{k}} \\
& \times\left\{\frac{U_{a}}{R_{1}+R_{2}}-\sqrt{2} I_{e} \frac{L_{2}-R_{2} \tau_{\text {sys }}}{L_{1}+L_{2}-\left(R_{1}+R_{2}\right) \tau_{\text {sys }}} e^{-T_{k} / \tau_{\mathrm{sys}}}\right. \\
&+\sqrt{2} I_{e} \frac{\omega L_{1} R_{2}-\omega L_{2} R_{1}}{\left(R_{1}+R_{2}\right)^{2}+\omega^{2}\left(L_{1}+L_{2}\right)^{2}} \sin \left(\omega T_{k}\right) \\
&+\sqrt{2} I_{e} \frac{\left(R_{1}+R_{2}\right) R_{2}+\omega^{2} L_{2}\left(L_{1}+L_{2}\right)}{\left(R_{1}+R_{2}\right)^{2}+\omega^{2}\left(L_{1}+L_{2}\right)^{2}} \cos \left(\omega T_{k}\right) \\
&+\sqrt{2} I_{e} \sin \left(\omega T_{k}+\alpha-\frac{\pi}{2}\right) \\
&\left.+\left[I_{e} \sin \left(\alpha-\varphi_{d}\right)-\sqrt{2} I_{e} \sin \left(\alpha-\frac{\pi}{2}\right)\right] e^{-T_{k} / \tau_{\text {sys }}}\right\} .
\end{aligned}
$$

The emulational value is deviated from the actual value, because arc resistance is assumed to be constant and unchanged with time in the model of transfer current. 


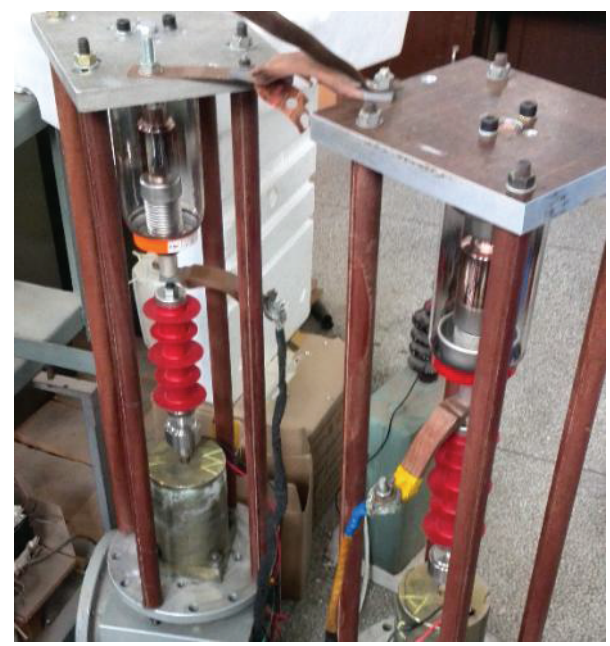

FIGURE 3: The two parallel breakers.

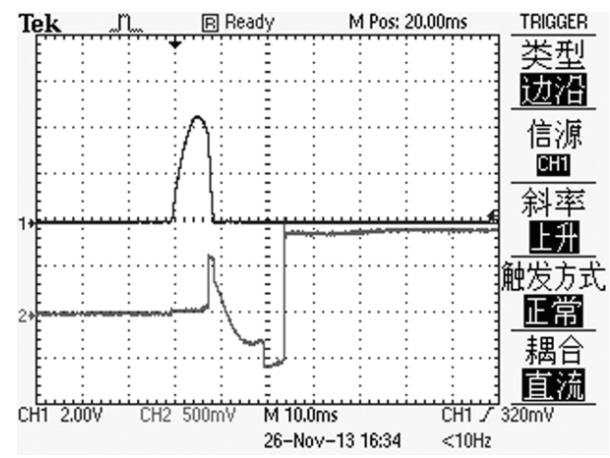

FIgURE 4: Transfer current of $5.2 \mathrm{ka}$ and voltage.

\section{Mathematical Model of Vacuum Arc Resistance}

In the experiment, two parallel breakers are used to share the large current as shown in Figure 3. The interrupter's model is BD-12/1250-20A produced by the Kaisaier. The large current is generated by the Synthesis loop. Its half cycle is $12.5 \mathrm{~ms}$ and the current's value is adjustable.

The two breakers controlled by the controller are opened according to the timing sequence. The current signal of the two breakers is collected by Rogowski coil and the arc voltage is collected by the resistance-type voltage divider that is parallel with the MVI. In Figures 4 and 5, the current value of 1200 A corresponds to $1 \mathrm{~V}$, which is the output of Rogowski coil. The curve 2 which is collected by resistance-type voltage divider amplified 22.6 times is the voltage between MVI. In this paper, the times of breaking MVI are $1.4 \mathrm{~ms}, 4.4 \mathrm{~ms}$, $5.0 \mathrm{~ms}, 6.2 \mathrm{~ms}, 7.0 \mathrm{~ms}$, and $8.3 \mathrm{~ms}$. The transfer currents are $3.7 \mathrm{ka}, 5.2 \mathrm{ka}, 6.4 \mathrm{ka}, 7.7 \mathrm{ka}$, and $9.6 \mathrm{ka}$. All current values are the peak of transfer currents.

The current that transfers from MVI to AVI is prevented by AVI's reactance. So the moment of breaking MVI needs to avoid the current's peak and it is better to choose the time in

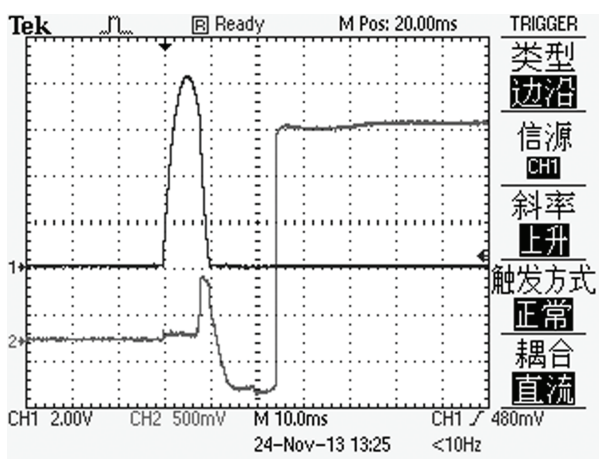

FIGURE 5: Transfer current of $9.6 \mathrm{ka}$ and voltage.

which current's value is relatively low. In the moment that is close to current's zero crossing, the success rate of transferring is higher. The enough computation-time of the controller is required to break AVI with the phase-control technology and the result in the moment is more obviously and more representatively compared with all experimental data. So the time of breaking MVI is selected at $8.3 \mathrm{~ms}$ in this paper. The waveforms of the oscilloscope are only listed in $5.2 \mathrm{ka}$ and $9.6 \mathrm{ka}$ due to limited space. MVI's current (curve 1) and the voltage (curve 2) across the interrupter are shown in Figures 4 and 5 .

In Figures 4 and 5, curve 2 is the voltage between MVI. At the beginning, the voltage is zero. When large current flows through MVI, its voltage has a slight uplift and maintains a stable value. At the moment at which MVI is opened, MVI's current drops rapidly and the arc is generated and the voltage pulse [14] increases immediately. The arc voltage is higher with the increase of transfer current. But the voltage's growth rate is low with the increase of transfer current. At the end of the transfer process, the arc is extinguished. The sinusoidal voltage is not the arc voltage but the voltage of AVI's branch in Figures 4 and 5. The voltage declines until AVI is opened. At the same time, the voltage pulse is the superposition of AVI's voltage and AVI's arc voltage in the negative half-cycle. Finally, the voltage is raised to the voltage of current source's capacitor and remains unchanged as shown in Figures 4 and 5.

It is shown how the MVI's and AVI's currents change in the first half-cycle when MVI is opened in Figures 6 and 7. MVI's current is 1.8 times larger than AVI's current before $8.3 \mathrm{~ms}$. The large current of the MVI is transferred from MVI to AVI at $8.3 \mathrm{~ms}$. In the transfer process, the MVI's arc voltage in $9.6 \mathrm{ka}$ is shown in Figure 8. Figure 8 is the amplification of arc voltage in Figure 5.

The real vacuum arc resistance is calculated with transfer current and arc voltage as shown in Figures 9 and 10.

The vacuum arc resistance is close to exponential growth. The arcing time becomes longer with the increase of transfer current. At the beginning of the transfer process, arc resistance grows very slowly at a low level. On the contrary, the arc resistance increases rapidly to a high value when the arc is extinguished. 


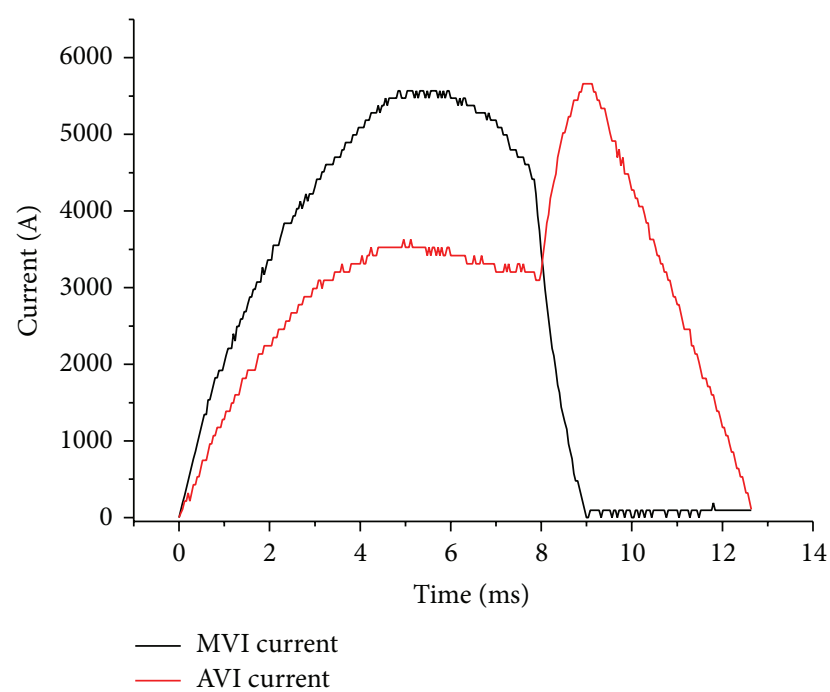

Figure 6: MVI's and AVI's currents in transfer current of $5.2 \mathrm{ka}$.

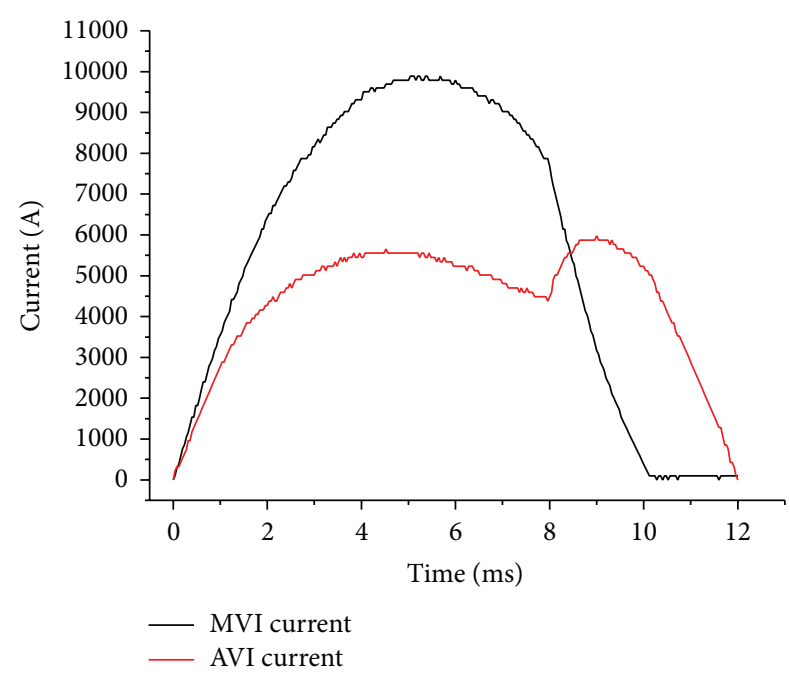

Figure 7: MVI's and AVI's currents in transfer current of $9.6 \mathrm{ka}$.

The mathematical formula of the arc resistance is expressed with (6) through the analysis of experimental data:

$$
\begin{gathered}
R_{\operatorname{arc}(t)}=a e^{b t}+600 \mu \Omega, \\
a=2.794 \times 10^{6} \times e^{\left[-3.024 \times 10^{-3}\left(2.892 \times 10^{-4} I^{2}{ }_{\mathrm{MVI}}-0.8731 I_{\mathrm{MVI}}+2729\right)\right]} \\
b=2.124 \times I_{\mathrm{MVI}}+2376 .
\end{gathered}
$$

In (6), $t$ is the arcing time. $I_{\mathrm{MVI}}$ is the transfer current.

The arc resistance is related with transfer current and arcing time. The arcing time becomes longer with the increase of the transfer current and the accumulation of heat becomes more and more. In (6), $a$ becomes smaller and $b$ becomes greater with the increase of the transfer current. In fact, arc resistance is related to contact material, the structure, the spacing of the contact, and so forth. The constants in (6) need to adjust in quite different experimental condition.

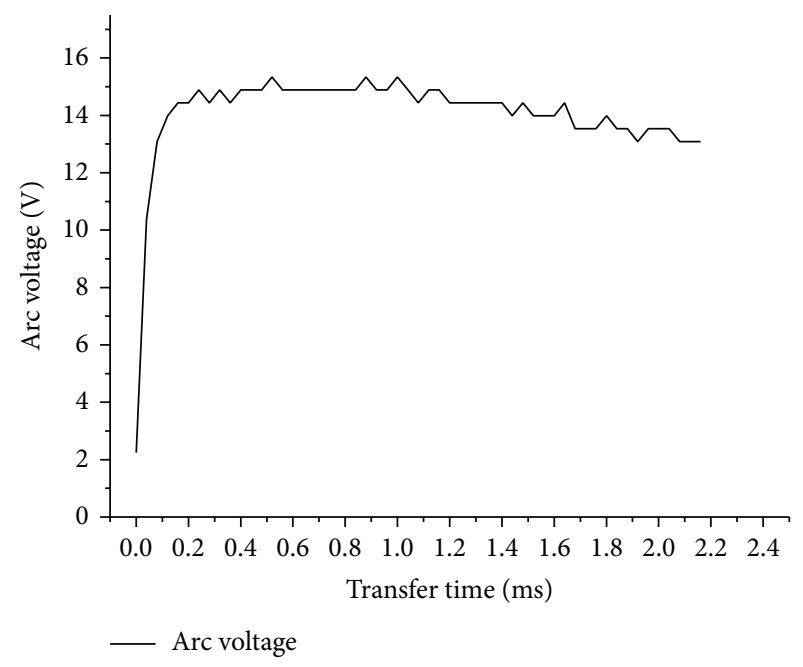

FIGURE 8: The arc voltage in the transfer process.

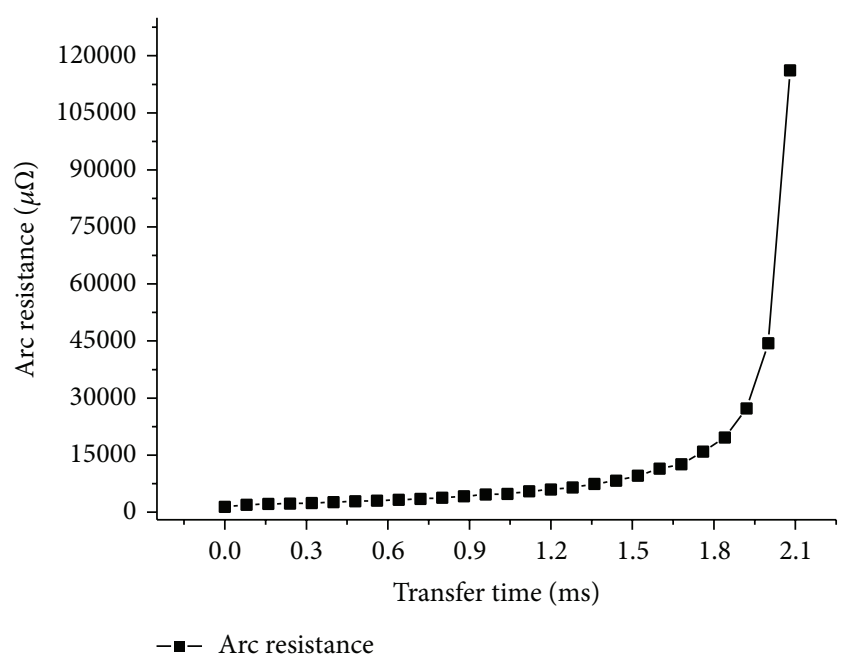

FIGURE 9: The vacuum arc resistance in transfer current of $9.6 \mathrm{ka}$.

The red points are the experimental data and the blue curve is the calculated value by the mathematical model of vacuum arc resistance. The calculated arc resistance is very close to the actual value with the model as shown in Figures $11,12,13$, and 14 .

\section{The Correctional Model of Transfer Current}

The $I_{(T 1)}$ is the part of particular solution of differential equation (3). At this moment, the arc is not generated and the $R_{1}$ remains constant. The constant $R_{1}$ in other items of (4) is replaced with $R_{1}+R_{\operatorname{arc}(t)}$ and the correctional model of transfer current is deduced as shown in the following:

$$
I_{(T 1)}=C e^{-\left(\left(R_{1}+R_{2}\right) /\left(L_{1}+L_{2}\right)\right) t}-\frac{U_{a}}{R_{1}+R_{2}} \quad(t=T 1),
$$




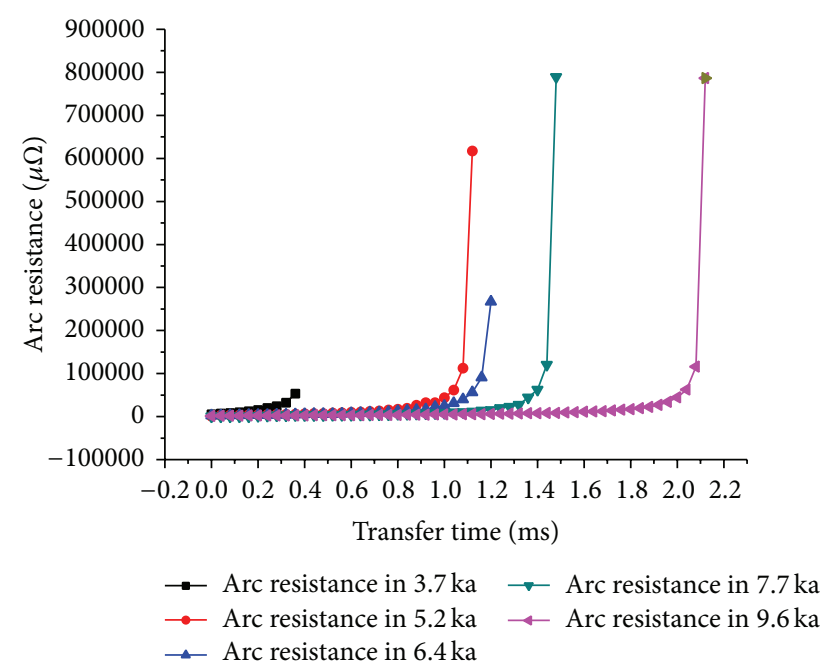

FIGURE 10: The vacuum arc resistance in all transfer currents.

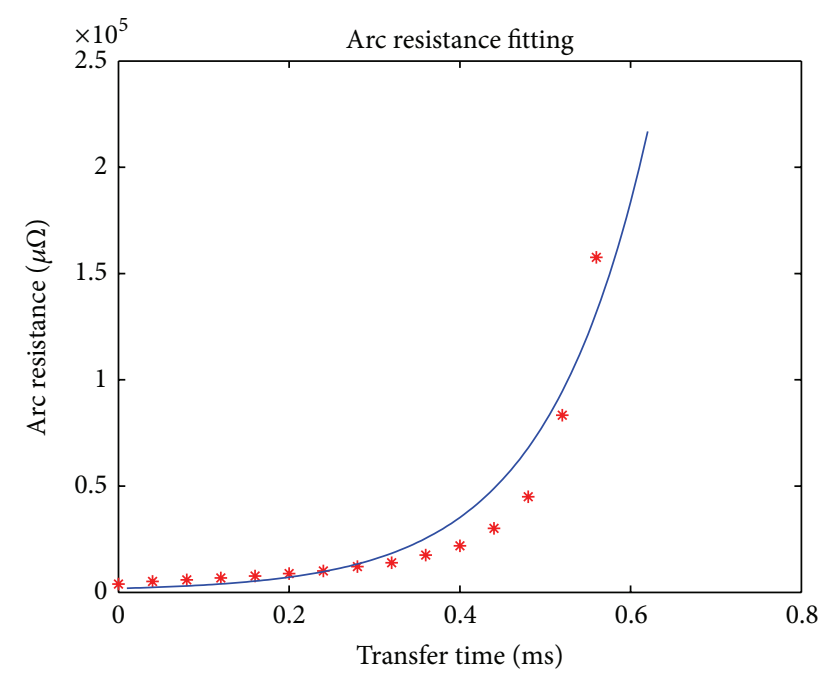

FIGURE 11: Arc resistance fitting in transfer current of $3.7 \mathrm{ka}$.

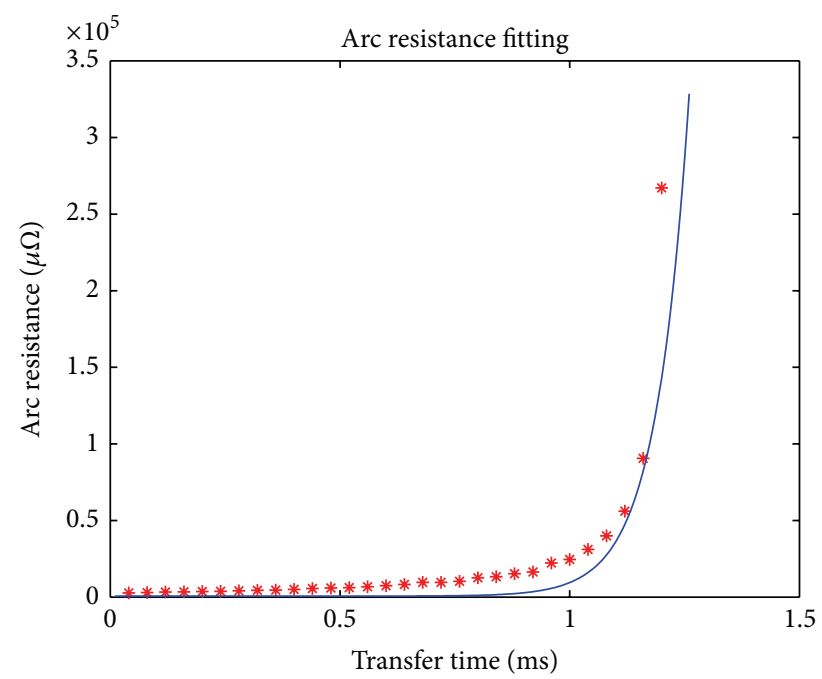

FIGURE 12: Arc resistance fitting in transfer current of $6.4 \mathrm{ka}$.

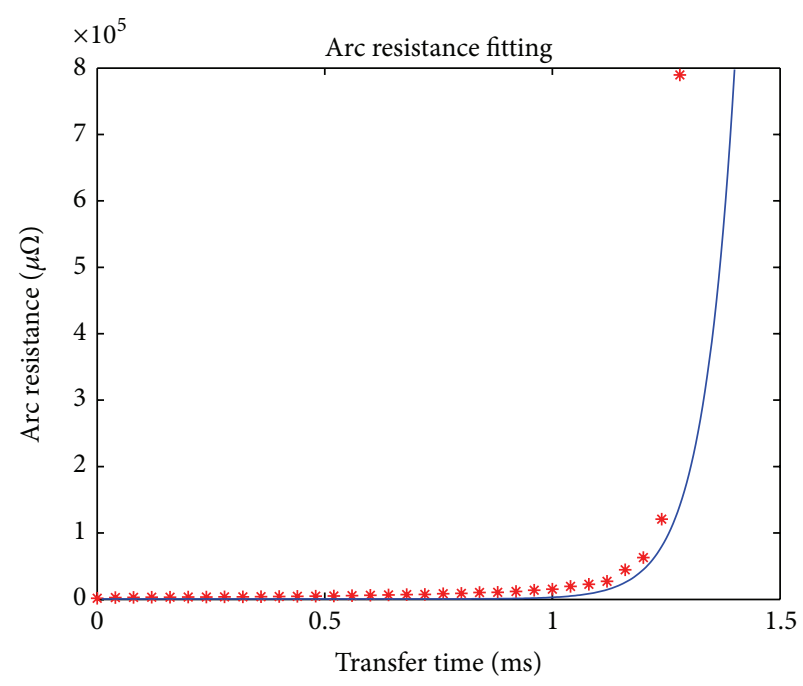

FIGURE 13: Arc resistance fitting in transfer current of $7.7 \mathrm{ka}$.

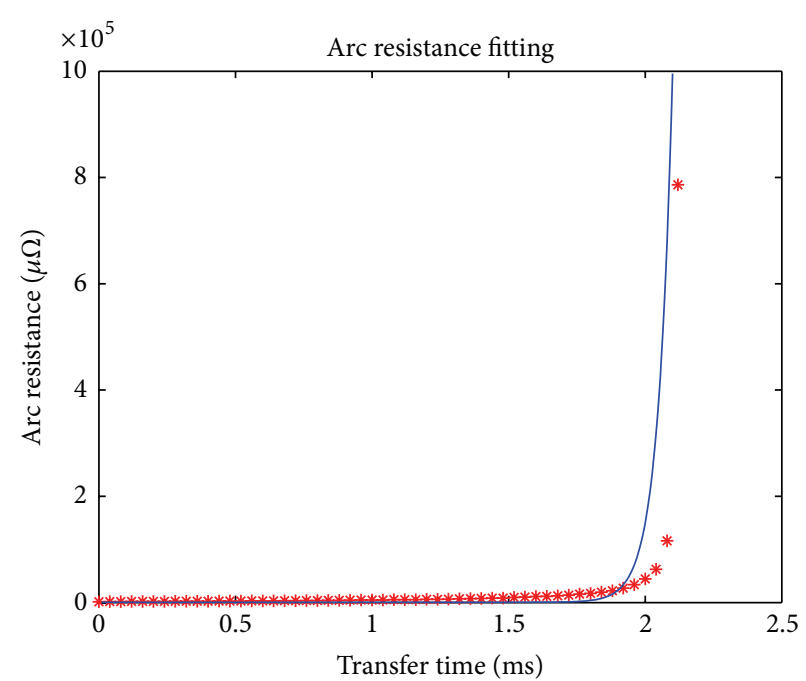

FIGURE 14: Arc resistance fitting in transfer current of $9.6 \mathrm{ka}$.

$$
\begin{aligned}
i_{1(t)}= & I_{(T 1)}+\sqrt{2} I_{e} \frac{L_{2}-R_{2} \tau_{\text {sys }}}{\left(L_{1}+L_{2}\right)-\left(R_{1}+R_{\operatorname{arc}(t)}+R_{2}\right) \tau_{\text {sys }}} e^{-t / \tau_{\text {sys }}} \\
& -\sqrt{2} I_{e} \frac{\omega L_{1} R_{2}-\omega L_{2}\left(R_{1}+R_{\operatorname{arc}(t)}\right)}{\left(R_{1}+R_{\operatorname{arc}(t)}+R_{2}\right)^{2}+\omega^{2}\left(L_{1}+L_{2}\right)^{2}} \sin (\omega t) \\
& -\sqrt{2} I_{e} \frac{\left(R_{1}+R_{\operatorname{arc}(t)}+R_{2}\right) R_{2}+\omega^{2} L_{2}\left(L_{1}+L_{2}\right)}{\left(R_{1}+R_{\operatorname{arc}(t)}+R_{2}\right)^{2}+\omega^{2}\left(L_{1}+L_{2}\right)^{2}} \\
& \times \cos (\omega t) \quad T 1<t \leq T 2 .
\end{aligned}
$$

The correctional transfer time is calculated with the correctional model of transfer current. The primary transfer time is calculated with the model of transfer current ((4)(5)) in Figures 15 and 16. The actual transfer time is the experimental data. 


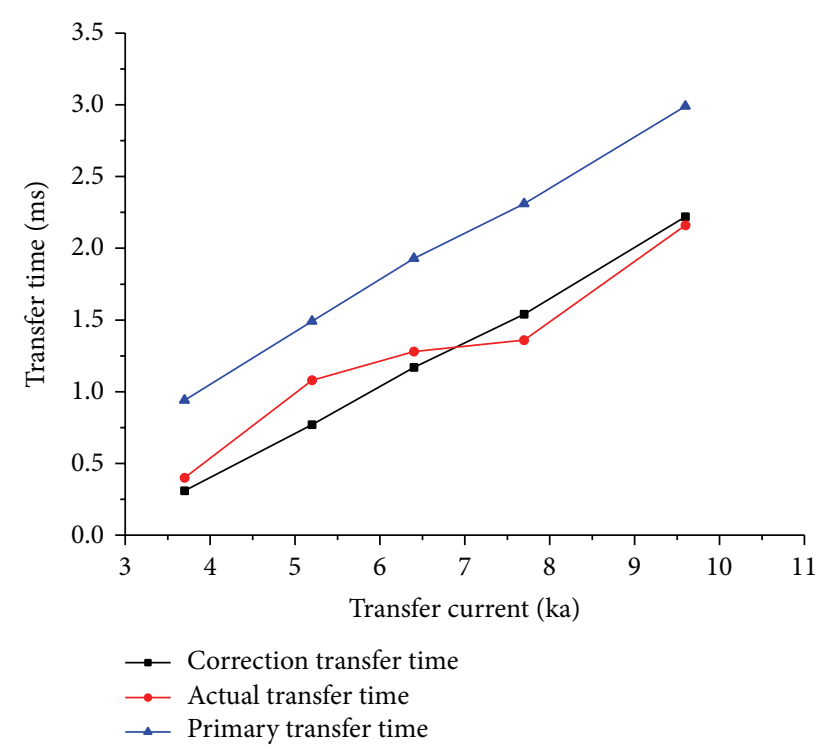

FIGURE 15: Three kinds of transfer time's comparison in different currents.

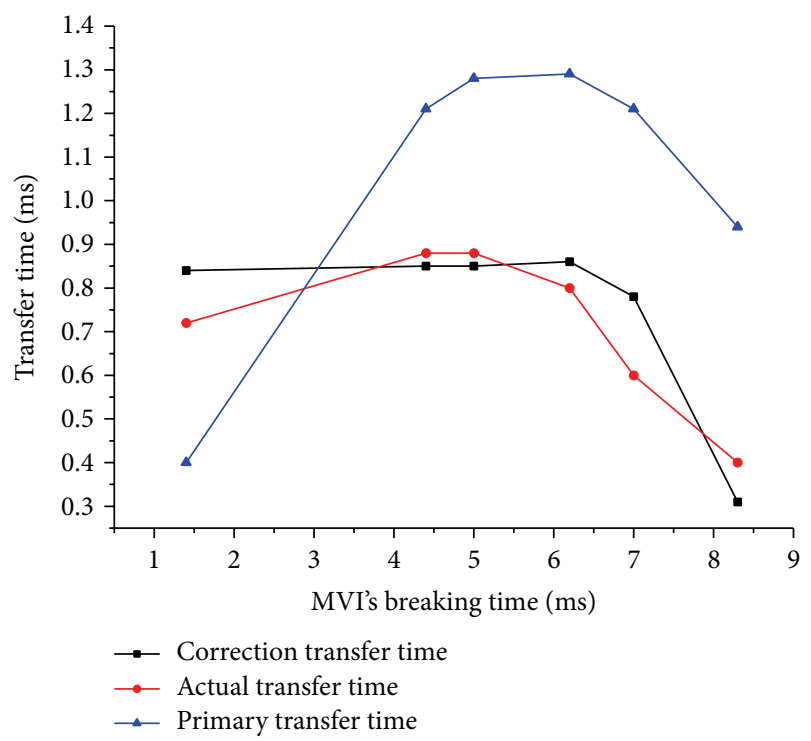

FIgURE 16: Three kinds of transfer time's comparison at different time of breaking MVI.

The comparison of the three kinds of transfer time in different current is shown in Figure 15 and the trend of transfer time at different times of breaking MVI is shown in Figure 16.

The correctional model of transfer current by analyzing experimental data with Matlab can accurately reflect the changing of the real vacuum arc resistance. The correctional model is more accurate and the correctional transfer time is closer to the actual transfer time. It can provide a proper timing sequence for breaking AVI with the phase-control technology.
So the correctional model can provide more accurate transfer time than the primary model for using the phasecontrol technology. The main contribution of the models can provide guidance for planning proper timing sequence and breaking a vacuum generator circuit breaker with the parallel interrupters.

Because the vacuum arc is affected by many factors, there is much work to research the more accurate vacuum arc's model.

\section{Conclusion}

The mathematical model of vacuum arc resistance and the correctional model of transfer current are established in this paper. By the analysis of experimental data and the results of simulation, the changing of real arc resistance is described and the real vacuum arc resistance is close to exponential growth. At the beginning of the transfer process, the arc resistance's growth rate is very low. But when the arc is extinguished, the real arc resistance increases rapidly to a high value. The arcing time becomes longer and the arc voltage is higher with the increase of the transfer current. At the same time, the duration of the low arc resistance's state maintains more time.

Although the mathematical model of vacuum arc resistance and the correctional model of transfer current are obtained under specific experimental condition, each of the important parameters in the models is adjustable according to specific circumstances. The real vacuum arc resistance's model and the correctional model of transfer current are widely applicable.

Because the transfer time calculated by the correctional model of transfer current is very close to the actual transfer time and the deviation is smaller, the models can provide proper guidance for breaking a large generator current with the phase-control technology.

As future work, there is much work to integrate the robust control algorithm [15] into the breakers and regulate the speed of breakers' movement. The authors plan to improve the scalability and fault tolerance [16] of the models at a satisfactory quality level and add the reciprocal determination process [17] where the models can take into account the speed of breakers and the type of fault current.

\section{Conflict of Interests}

The authors declare that there is no conflict of interests regarding the publication of this paper.

\section{Acknowledgment}

This work is supported by the National Natural Science Foundation of China (no. 51277019).

\section{References}

[1] CIGRE Working Group 13.07, Controlled Switching of HV AC Circuit Breaker Guidance For Further Application Including 
UnLoaded transFormer Switching, Load and Fault Interruption and Circuit Breaker Uprating, CIGRE, Chengdu, China, 1999.

[2] A. Poltl and K. Frohlich, "A new algorithm enabling controlled short circuit interruption," IEEE Transactions on Power Delivery, vol. 18, no. 3, pp. 802-808, 2003.

[3] X.-S. Chen and J. Zou, "Generator protection vacuum circuit breaker," High Voltage Apparatus, vol. 36, no. 1, pp. 34-37, 1998.

[4] M. Homma, M. Sakaki, E. Kaneko, and S. Yanabu, "History of vacuum circuit breaker and recent development in Japan," in Proceedings of the 21th International Symposium on Discharges and Electrical Insulation in Vacuum (ISDEIV '04), pp. 378-383, Yalta, Ukraine, October 2004.

[5] P.-H. Zhou, M. Dai, Y. Lou, and M.-H. Xiu, "DC component time constant and zero off set phenomena of breaking current for $1000 \mathrm{kV}$ circuit breaker," High Voltage Engineering, vol. 35, no. 4, pp. 722-730, 2009.

[6] L.-J. Cao and J. Li, "Exploration on high capacity generate or outlet protection vacuum circuit breaker," Electrical Device, vol. 5, no. 9, pp. 84-85, 2004.

[7] X.-S. Chen, J.-Y. Zou, and J.-J. - He, "Parallel high-current vacuum arc breaking," High Voltage Apparatus, no. 4, pp. 2932, 1997.

[8] M. Matsukawa, Y. M. Miura, T. Terakado et al., "Development of a vacuum switch carrying a continuous current of $36 \mathrm{kA} \mathrm{DC}$," in Proceedings of the 19th International Symposium on Discharges and Electrical Insulation in Vacuum, vol. 2, pp. 415-418, 2000.

[9] X.-S. Chen, Z.-W. Wang, J.-Y. Zou et al., "Experiment al research on paralleled breaking process of vacuum circuit breaker," High Voltage Apparatus, vol. 33, no. 5, pp. 33-37, 1998.

[10] X.-Y. Duan, M.-F. Liao, F.-H. Ding, and J.-Y. Zou, "Application and key technology analysis of controlled switching," High Voltage Apparatus, vol. 43, no. 2, pp. 113-117, 2007.

[11] X. Duan, M. Liao, F. Ding, B. Liu, and J. Zou, "Controlled vacuum circuit breaker for shunt capacitor banks," Transactions of China Electrotechnical Society, vol. 22, no. 10, pp. 78-84, 2007.

[12] F.-H. Ding, J.-Y. Zou, and X.-Y. Duan, "Research on optimum switching phase of phasing switches," High Voltage Apparatus, vol. 41, no. 6, pp. 408-411, 2005.

[13] X. Zheng, J.-Y. Zou, and Z. Cheng, "Current transfer process of paralleled vacuum generator circuit breaker," High Voltage Engineering, vol. 35, no. 11, pp. 2709-2715, 2009.

[14] Z.-Y. Liu, J.-M. Wang, Z.-Y. Wang, and S. Yuan, "Current transfer process in open operation between parallel breaks of a vacuum generator circuit breaker," Proceedings of the Chinese Society of Electrical Engineering, vol. 20, no. 12, pp. 20-23, 2000.

[15] V. Veselly and D. Rosinova, "Robust MPC controller design for switched systems using multi- parameter dependent lyapunov function," International Journal of Innovative Computing, Information and Control, vol. 10, no. 1, pp. 269-280, 2014.

[16] C. Dobre, "A cluster-enhanced fault tolerant peer-to-peer systems," International Journal of Innovative Computing, Information and Control, vol. 10, no. 2, pp. 417-436, 2014.

[17] K. Harada and Y. Ishida, "Complex spatial-temporal patterns developed from an interaction of functions and data," International Journal of Innovative Computing, Information and Control, vol. 10, no. 1, pp. 405-416, 2014. 


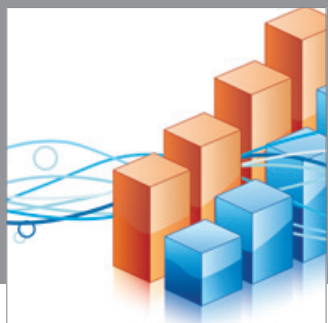

Advances in

Operations Research

mansans

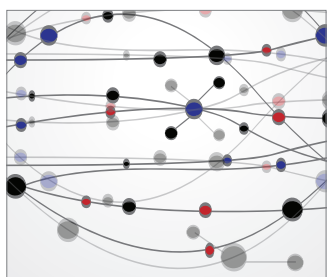

The Scientific World Journal
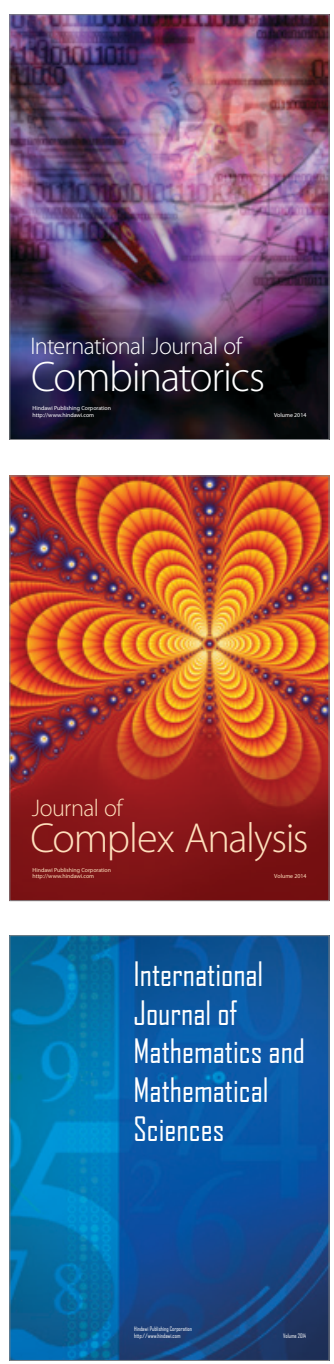
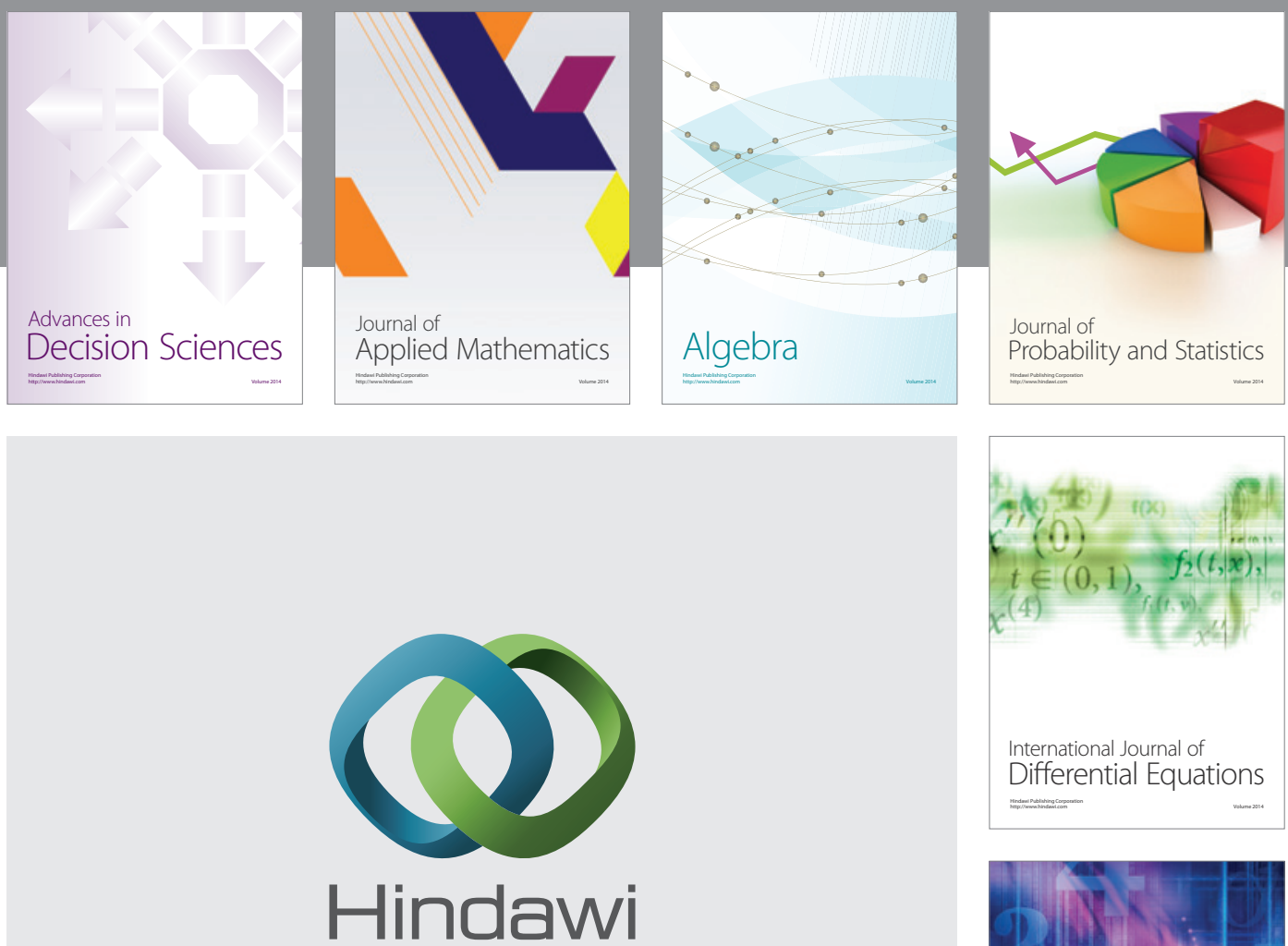

Submit your manuscripts at http://www.hindawi.com
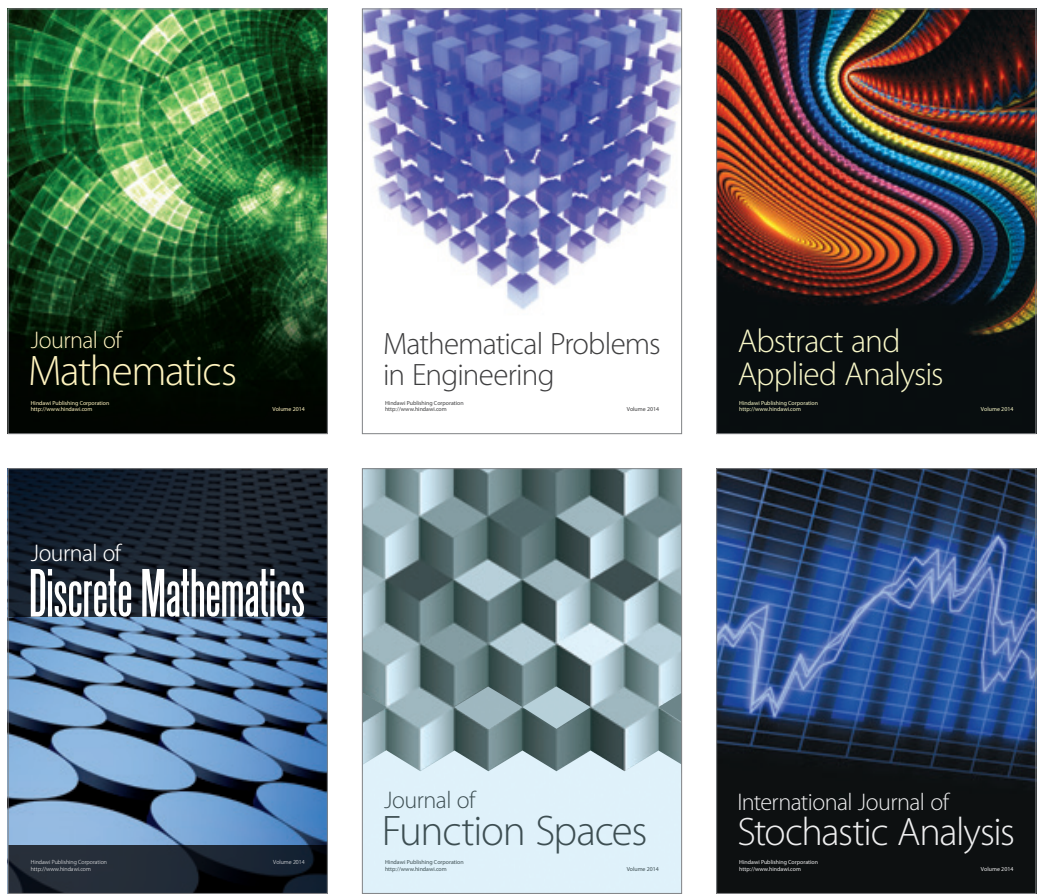

Journal of

Function Spaces

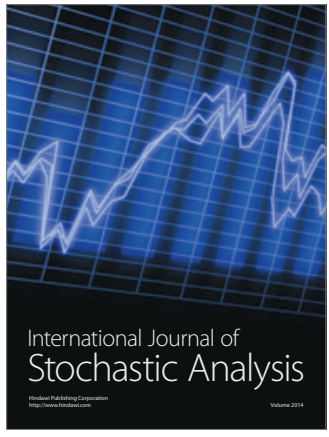

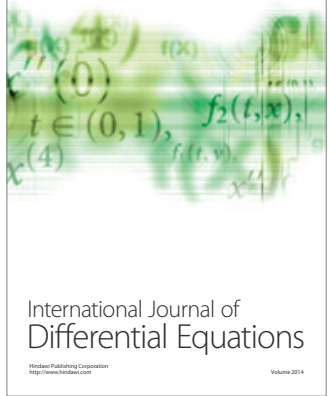
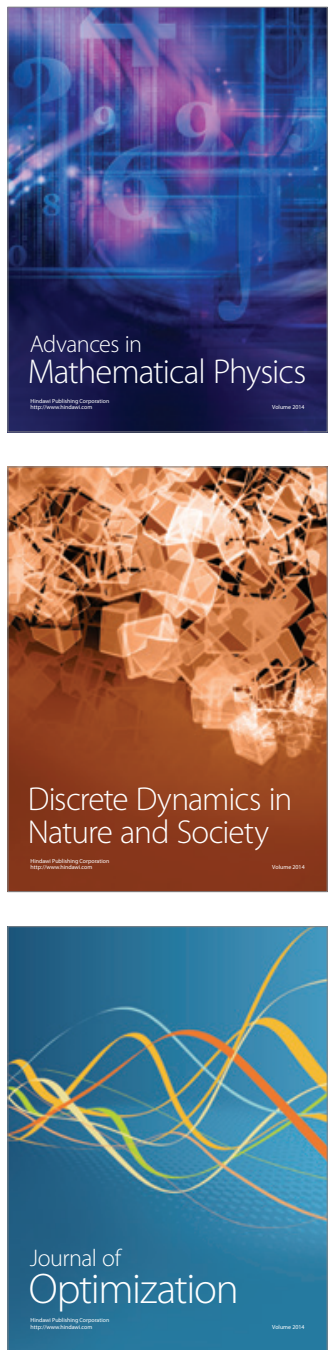